\title{
Preventive Effect of Eye Drops of Liposomes Containing Disulfiram and Cefmetazole on Selenite-Induced Cataract in Rat Pups
}

\author{
Yoshimasa Ito $^{1 *, 2}$, Noriaki NAGAI ${ }^{1}$, Hong CAI $^{1}$, Maki TAKedA $^{1}$ and Yuichi KoIzumi ${ }^{1}$ \\ ${ }^{1}$ School of Pharmaceutical Sciences, Kinki University \\ (3-4-1 Kowakae, Higashi-Osaka, Osaka 577-8502, JAPAN) \\ ${ }^{2}$ Pharmaceutical Research and Technology Institute, Kinki University \\ (3-4-1 Kowakae, Higashi-Osaka, Osaka 577-8502, JAPAN)
}

Edited by M. Ohnishi, Obihiro Univ. Agric. Veter. Med., and accepted August 31, 2005 (received for review July 15, 2005)

\begin{abstract}
Disulfiram (DSF) and cefmetazole (CMZ), which possess with anti-oxidative activities were tested for anti-cataract effect in rats and were compared with pirenoxine (PRX), which is a marketed product used for the treatment of cataract. These compounds were encapsulated in liposomes and the results were compared with the anti-cataract effect of suspension and solution formulations containing same contents of each other agents. Instillations of DSF- and CMZ-liposomes prevented the development of cataract in seleniteinjected rat pups. On the other hand, no anti-cataract effects were observed in selenite-induced cataract rats instilled with DSF suspensions and CMZ solutions. The reduced form of glutathione (GSH) content of the lenses was decreased by approximately $60 \%$ of normal level 96 $\mathrm{h}$ after the sodium selenite-injection and the calcium $\left(\mathrm{Ca}^{2+}\right)$ content was increased. The decreased GSH and increased $\mathrm{Ca}^{2+}$ levels were prevented by instillation of DSF- and CMZliposomes. Instillation of PRX-liposomes and $0.03 \%$ PRX solution had no effect on the development of cataract. The results of this study confirmed that anti-oxidative agents such as DSF and CMZ were useful to prevent cataract development related to oxidative stress.
\end{abstract}

Key words: eye drop, cataract, antioxidant, disulfiram, cefmetazole

\section{Introduction}

Current hypotheses concerning the pathogenesis of senile cataracts in human patients include osmotic shock (1), genetic defects (2-4), or oxidative damage (5-8). Analyses of the lenses and aqueous humor from the eye of patients with senile cataracts has demonstrated increased hydrogen peroxide $\left(\mathrm{H}_{2} \mathrm{O}_{2}\right)$ levels (9) and decreased reduced form of glutathione (GSH) levels (10) accompanied by extensive damages of protein $(3,11)$, lipid (12) and DNA (1), suggesting the participation of reactive oxygen species (ROS). ROS scav- engers such as vitamin $C(13,14)$, vitamin $E(15,16)$, or GSH (17) inhibited the onset of cataracts and protected the crystalline protein of the lens. These studies suggest the possible use of agents that suppress ROS formation for the therapeutic or prophylactic treatment of cataracts.

Disulfiram (DSF) has been widely used in the treatment of alcohol abuse (18) to inhibit the liver enzyme, aldehyde dehydrogenase (19). Diethyldithiocarbamate (DDC) is produced from DSF by the catalytic reaction of sulfhydryl groups in proteins such as albumin (20). DDC has been shown to inhibit microsomal lipid perox-

\footnotetext{
${ }^{*}$ Correspondence to: Yoshimasa ITO, School of Pharmaceutical Sciences, Kinki University, 3-4-1 Kowakae, Higashi-Osaka, Osaka 577-8502, JAPAN

E-mail: itoyoshi@phar.kindai.ac.jp
} 
idation in rat hepatocytes (21) and DSF and DDC have been reported to inhibit DNA breakage by hydroxyl radicals (22). Moreover, it has been reported that thiomethyltetrazole (23) also has an anti-oxidative activity and antabuse effect.

In this study we examined the anti-cataract effects of DSF, cefmetazole (CMZ, one of cephamycins that possesses a thiomethyltetrazole residue in its structure) (24), and pirenoxine (PRX) (25-27) which is already marketed for clinical use in Japan (Fig. 1). The anticataract effects were monitored by the ability for prevention of selenite induced cataracts in rat pups (28). We also investigated the effectiveness of liposome formulation as a carrier for these drugs.

\section{Experimental}

\section{2・1 Animals}

Male and female Wistar rat pups aged 13 days old were used. They were housed under standard conditions of $12 \mathrm{~h}$ /day fluorescent light (07:00-19:00) and $25^{\circ} \mathrm{C}$ room temperature and were given a commercial diet (CE-2, Clea Japan Inc., Tokyo, Japan) and water $a d$ libitum (rat pups were kept with their mother). All animal studies were conducted in accordance with the NIH

$$
\begin{aligned}
& \mathrm{C}_{2} \mathrm{H}_{5}>\mathrm{N}-\mathrm{S} \\
& \mathrm{C}_{2} \mathrm{H}_{5}>\mathrm{C}-\mathrm{S}-\mathrm{S}-\mathrm{S}-\mathrm{C}-\mathrm{N}> \\
& \mathrm{C}_{2} \mathrm{H}_{5} \\
& \mathrm{C}_{2} \mathrm{H}_{5}>\mathrm{C}-\mathrm{SI} \\
& \mathrm{C}_{2} \mathrm{H}_{5}>\mathrm{N}-\mathrm{CH}
\end{aligned}
$$<smiles>O=C(O)c1cc(O)c2c3nc4ccccc4oc-3cc(=O)c2n1</smiles>

DDC

PRX

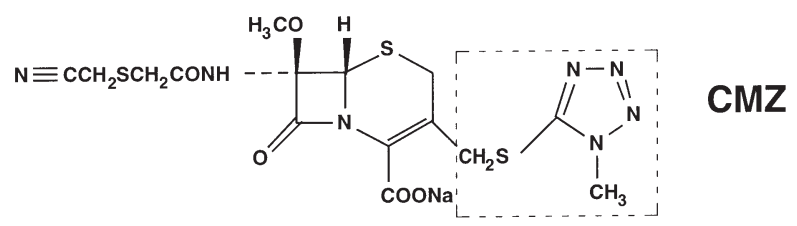

Fig. 1 Structures of the Compounds Tested for AntiAataract Activity. The part of the structure within the dotted outline represents a residue of thiomethyltetrazole.
Guidelines on the Care and Use of Animals in Research.

\section{$2 \cdot 2$ Chemicals}

DSF was kindly donated by Ouchi Shinko Chemical Industrial Co., Ltd. (Tokyo, Japan). PRX was purchased as a commercial granulated product (Catalin K, Senju Pharmaceutical Co., Osaka, Japan). CMZ was a commercial product (antibiotics for injection, Sankyo Pharmaceutical Co., Tokyo, Japan). Sodium selenite was purchased from Wako Pure Chemical Industries Ltd. (Osaka, Japan). Dipalmitoylphosphatidylcholine (DPPC) and dimyristoylphosphatidylcholine (DMPC) were obtained from Nippon Oil and Fats Co., Ltd. (Tokyo, Japan). 1-n-Hexa-decylpyridinum chloride monohydrate (CPC) was purchased from Kanto Chemical Co. (Tokyo, Japan). All other chemicals used were of the highest purity and were commercially available.

\section{$2 \cdot 3$ Determination of DSF, CMZ and PRX in Liposomes}

The amount of DSF in the liposomes was determined by an HPLC method previously described (29). Fifty $\mu \mathrm{L}$ of the sample solution was added to $100 \mu \mathrm{L}$ of the internal standard solution ( $5 \mu \mathrm{g}$ of indomethacin $/ \mathrm{mL}$ of methanol). Two $\mu \mathrm{L}$ of the mixture was injected into an HPLC instrument, Shimadzu LC-10AD, equipped with a column oven, CTO-6A. The chromatography was performed under the following conditions: a Wakosil-II $3 \mathrm{C} 18$ AG $(4.6 \times 150 \mathrm{~mm}$, Wako Pure Chemical Industries, Ltd., Osaka, Japan) column, mobile phase of $60 \%$ acetonitrile containing $0.1 \%$ trifluoroacetic acid, flowrate of $1.0 \mathrm{~mL} / \mathrm{min}$, column temperature of $35^{\circ} \mathrm{C}$ and a $215 \mathrm{~nm}$ wavelength for detection.

The amount of CMZ in the liposomes was determined by an HPLC method. Fifty $\mu \mathrm{L}$ of the sample solution was added to $100 \mu \mathrm{L}$ of the internal standard solution ( $30 \mu \mathrm{g}$ of L-tryptophan $/ \mathrm{mL}$ of methanol). Two $\mu \mathrm{L}$ of the mixture was injected into an HPLC instrument, Shimadzu LC-10AD, equipped with a column oven, CTO-6A. The chromatography was performed under the following conditions: a Capcell Pack C18 (4.6 $\times 150 \mathrm{~mm}$, Shiseido Co., Ltd., Tokyo, Japan) column, mobile phase of $50 \mathrm{mM}$ soudium citrate buffer (pH 5.0) containing 8\% acetonitrile, flow-rate of 1.0 $\mathrm{mL} / \mathrm{min}$, column temperature of $35^{\circ} \mathrm{C}$ and a $254 \mathrm{~nm}$ wavelength for detection.

The amount of PRX in the liposomes was determined 
by an HPLC method described in Japanese Pharmacopoeia (30). Fifty $\mu \mathrm{L}$ of the sample solution was added to $100 \mu \mathrm{L}$ of the internal standard solution ( $5 \mu \mathrm{g}$ of methyl-p-hydroxybenzoate $/ \mathrm{mL}$ of methanol). Two $\mu \mathrm{L}$ of the mixture was injected into an HPLC instrument, Shimadzu LC-10AD, equipped with a column oven, CTO6A. The chromatography was performed under the following conditions: a Capcell Pack C18 $(4.6 \times 150 \mathrm{~mm}$, Shiseido Co., Ltd., Japan) column, mobile phase of 10 $\mathrm{mM}$ soudium phosphate buffer ( $\mathrm{pH}$ 6.5) containing $25 \%$ acetonitrile, $0.15 \%$ tetra- $n$-butylammonium chloride and $3.5 \%$ tetrahydrofuran, flow-rate of 1.0 $\mathrm{mL} / \mathrm{min}$, column temperature of $35^{\circ} \mathrm{C}$ and a $230 \mathrm{~nm}$ wavelength for detection.

\subsection{Preparation of Liposomes Containing DSF, CMZ and PRX and DSF Suspen- sions}

Liposomes containing DSF (DSF-liposomes) were prepared by reverse phase solvent evaporation with a minor modification (31). DSF (10 mg), DPPC (201 $\mathrm{mg}$ ), DMPC (750 mg) and CPC (49 mg) were dissolved in $20 \mathrm{~mL}$ of dichloromethane. The molar ratio of DPPC, DMPC and CPC was 2:8:1 and the total weight was $1.0 \mathrm{~g}$. This solution was used as the hydrophobic phase. The hydrophobic phase was mixed with $10 \mathrm{~mL}$ of phosphate buffered saline ( $\mathrm{pH} 7.4$ ) containing $0.04 \%$ methyl and $n$-propyl $p$-hydroxybenzoate and was sonicated under a stream of nitrogen using a bath-type sonicator (Branson Ultrasonics Division EmersonJapan, Yokohama, Kanagawa, Japan). The w/o emulsion was aspirated for $30 \mathrm{~min}$ at $37^{\circ} \mathrm{C}$ to remove the dichloromethane. The liposomes were passed through an Extluder ${ }^{\circledR}$ (Lipex Biomembranes Inc., Vancouver, Bc., Canada) with polycarbonate membranes (pore sizes of 1.0, 0.6, 0.2 and $0.1 \mu \mathrm{m}$, Coster Scientific Corp., Cambridge, Ma., USA), which was repeated 10 times for each membrane. The particle sizes of the liposomes were determined using a laser diffraction scattering particle analyzer, Coulter N4S (Coulter Corp., U.S.A.). The particle size of the liposomes was approximately $80 \mathrm{~nm}$ and the DSF content was $0.98 \pm$ $0.08 \mathrm{mg} / \mathrm{mL}$.

Liposomes containing CMZ (CMZ-liposomes) or PRX (PRX-liposomes) were prepared by the same method that was used for DSF-liposomes except CMZ and PRX were dissolved in a buffer solution and a different molar ratio of phospholipids was used. DPPC
(774 mg), DMPC (179 mg) and CPC (47 mg) were dissolved in $20 \mathrm{~mL}$ of dichloromethane which was used as the lipophilic phase. The molar ratio of DPPC, DMPC and CPC was 8:2:1 and the total weight was $1.0 \mathrm{~g}$. The lipophilic phase was mixed with $10 \mathrm{~mL}$ of CMZ solution $(1000 \mathrm{mg} / \mathrm{mL})$ or PRX $(0.3 \mathrm{mg} / \mathrm{mL})$ dissolved in buffer and was sonicated under a stream of nitrogen. The emulsion was aspirated for $30 \mathrm{~min}$ at $37^{\circ} \mathrm{C}$ to remove dichloromethane. The liposomes were passed through an Extluder ${ }^{\circledR}$ with polycarbonate membranes (pore sizes of 1.0, 0.6, 0.2 and $0.1 \mu \mathrm{m}$ ) in the same manner as described above. To separate the liposomes from the unencapsulated CMZ or PRX, the liposomes were chromatographed on a column of Superose 6 (2.5 $\times 30.0 \mathrm{~cm}$, Pharmacia LKB Biotechnology AB, Uppsala, Sweden) equilibrated with $10 \mathrm{mM}$ sodium phosphate buffer ( $\mathrm{pH}$ 7.4) containing $145 \mathrm{mM} \mathrm{NaCl}$ and 1 mM EDTA. The white turbid fractions were collected and used as CMZ- or PRX-liposome preparations. The particle size of the liposomes was approximately 100 $\mathrm{nm}$ and the CMZ and PRX contents were $32.3 \pm 8.7$ $\mathrm{mg} / \mathrm{mL}$ and $0.24 \pm 0.02 \mathrm{mg} / \mathrm{mL}$, respectively.

DSF suspensions were prepared by a solvent evaporation method. One hundred $\mathrm{mg}$ of DSF was dissolved in $30 \mathrm{~mL}$ of dichloromethane and this solution was filtered through a membrane filter $(0.22 \mu \mathrm{m}$ of pore size $)$. The DSF solution was mixed with $50 \mathrm{~mL}$ of phosphate buffered saline ( $\mathrm{pH}$ 7.4) containing $0.04 \%$ methyl and $n$-propyl $p$-hydroxybenzoate and was sonicated for 10 min. The emulsion was aspirated for $1 \mathrm{~h}$ at room temperature to remove the organic solvent. The DSF suspension $(2 \mathrm{mg} / \mathrm{mL})$ was diluted with an equal volume of the same buffer containing $0.5 \%$ hydroxypropylmethylcellulose 2906 (Shin-Etsu Chemical Co., Tokyo, Japan). The particle size of DSF in the suspension was $18.6 \pm 2.6 \mu \mathrm{m}$, and the final content of DSF in the suspensions was $1.02 \pm 0.06 \mathrm{mg} / \mathrm{mL}$.

Solutions of $3.0 \% \mathrm{CMZ}$ and $0.03 \%$ PRX were prepared by dissolving each solid agent in $10 \mathrm{mM}$ sodium phosphate buffer ( $\mathrm{pH}$ 7.4) containing $145 \mathrm{mM} \mathrm{NaCl}$.

\subsection{Selenite-Induced Cataracts of Rats and Treatment by DSF-, CMZ- and PRX-liposomes}

For the induction of cataracts, rat pups aged 13 days were given a single subcutaneous injection of sodium selenite dissolved in $0.9 \% \mathrm{NaCl}$ solution $(19 \mu \mathrm{mol} / \mathrm{kg}$ body weight) (28). The eyelids of rat pups were opened 
gently and carefully with blunt tweezers. Five $\mu \mathrm{L}$ of liposomes containing DSF $(0.98 \mathrm{mg} / \mathrm{mL}), \mathrm{CMZ}(32.3$ $\mathrm{mg} / \mathrm{mL})$ or PRX $(0.24 \mathrm{mg} / \mathrm{mL})$ were instilled into the eyes. The eyes were kept open for approximately one minute to prevent the liposomes from overflowing. The treatment for both eyes was completed $1.5 \mathrm{~h}$ before the sodium selenite injection and was repeated 4 times per day (at times of 06:30, 12:00, 18:00, 23:00) for one week after the selenite injection. Both eyes of the control group rats were instilled with agent free liposomes as described above. Rat pups were killed by decapitation and bled out at selected time points after sodium selenite injection and the lenses were removed from the eye. All animals were alive during the monitoring of lens opacification.

\subsection{Determination of Reduced Form of Glutathione (GSH), Sodium $\left(\mathrm{Na}^{+}\right)$, Potassium $\left(\mathrm{K}^{+}\right)$and Calcium $\left(\mathrm{Ca}^{2+}\right)$ Ions in Lenses of Selenite-Induced Cataract Rats}

The GSH and $\mathrm{Na}^{+}, \mathrm{K}^{+}$, and $\mathrm{Ca}^{2+}$ ions in the lenses were measured as described below.

GSH levels were assayed by the HPLC method of Tsunasawa with minor modifications (32). The lenses were homogenized in $0.5 \mathrm{~mL}$ of purified water using a Teflon tissue homogenizer. GSH in the homogenate was determined by the following HPLC method. Fifty $\mu \mathrm{L}$ of the lens homogenate were added into $100 \mu \mathrm{L}$ of acetonitrile containing $10 \mu \mathrm{g}$ of sodium pantothenate (internal standard) and centrifuged at 12,000 rpm for 10 min. The supernatant $(10 \mu \mathrm{L})$ was injected into a Supersphere $100 \mathrm{RP}-18(4 \mu \mathrm{m}$, column size: $4.0 \times 250$ $\mathrm{mm}$ ) column (Kanto Chemical Co., Inc., Tokyo, Japan), using a Shimadzu LC-10AD system equipped with a column oven CTO-6A (Shimadzu Corp., Kyoto, Japan). The mobile phase consisted of 5\% methanol containing $0.1 \%$ trifluoroacetic acid. The flow rate was 1.0 $\mathrm{mL} / \mathrm{min}$, the column temperature was $35^{\circ} \mathrm{C}$, and the wave length for detection was $215 \mathrm{~nm}$.

$\mathrm{Na}^{+}, \mathrm{K}^{+}$and $\mathrm{Ca}^{2+}$ contents of the lenses were assayed by the method of Bunce et al. with minor modification (33). The lenses were dried in a vacuum at $100^{\circ} \mathrm{C}$ for 8 $\mathrm{h}$ and then digested in $60 \%$ nitric acid $(100 \mu \mathrm{L} / \mathrm{lens})$ at $80^{\circ} \mathrm{C}$. One $\mathrm{mL}$ of purified water was added to the digests and the tubes were centrifuged at $300 \times \mathrm{g}$ for 10 min. Two tenth $\mathrm{mL}$ of the supernatant was mixed with $2 \mathrm{~mL}$ of purified water for the $\mathrm{Na}^{+}$and $\mathrm{K}^{+}$assays. One tenth $\mathrm{mL}$ of $100 \mu \mathrm{g} / \mathrm{mL}$ lanthanum chloride was added to the supernatant for the determination of the $\mathrm{Ca}^{2+}$ content. The $\mathrm{Na}^{+}, \mathrm{K}^{+}$and $\mathrm{Ca}^{2+}$ levels in the lenses were determined by atomic absorption spectroscopy, Shimadzu AA-6400 (Shimadzu Corp., Kyoto, Japan).

\section{$\mathbf{2} \cdot \mathbf{7}$ Image Analysis}

Lens opacification was observed with a Scheimpflug camera and recorded at selected time points from 0 to 7 days. The pupils of the rat pups were dilated with $1 \%$ pivalephrine (Santen Pharmaceutical Co., Ltd., Osaka, Japan) without anesthesia $5 \mathrm{~min}$ before taking slit photographs using a photoslit lamp microscope and an anterior eye segment analysis system (EAS-1000, Nidek, Gamagori, Aichi, Japan) at selected time points from 24 to $96 \mathrm{~h}$. The lens images were obtained using an EAS-1000 equipped with a CCD camera. Flash level was 100 Watt-seconds and the slit length was 4.4 $\mathrm{mm}$. The area of the opacity, in pixels, was analyzed using an EAS-1000 $(34,35)$. The outline of the slit lens image was determined by selecting 4 points on the image. Then the transparent area within the lens outline and threshold level were set automatically by the computer software. There are approximately 100 threshold levels both for a normal lens and a lens with a cataract. The total area of opacity of the lenses, expressed as pixels, was calculated by the following equation:

Pixels within opacity $=$ pixels within outline - pixels within transparent area

\subsection{Statistical Analysis}

All values were expressed as the means \pm SEM in a total of 3 to 8 experiments. Significance of the mean differences in each experiment was analyzed by Student's $t$-test, and a $p$ value of $<0.05$ was considered significant.

\section{Results}

Figure 2 shows the Scheimpflug camera images of eyes from rats $96 \mathrm{~h}$ after selenite injection. The lenses had significant opacity in the nuclear portion of the lenses (positive control). On the other hand, the lenses from selenite-injected rats treated with DSF-liposomes were similar in transparency to those from control rats. The lenses of selenite injected rats treated with CMZliposomes were either clear or had a trace of opacity in 

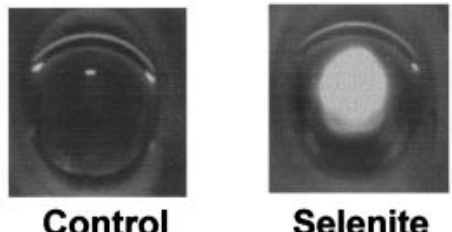

Selenite
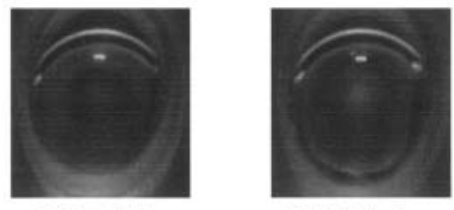

DSF-Lipo

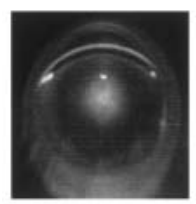

DSF-Susp
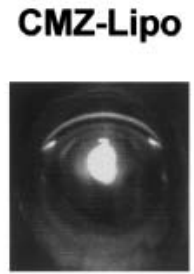

CMZ-Soln

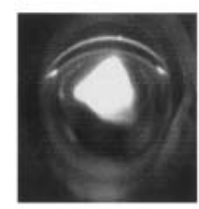

PRX-Lipo

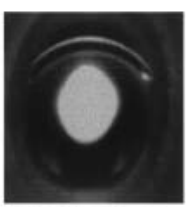

PRX-Soln

Fig. 2 Slit Images of Eyes from Selenite-Injected Rat Pups Instilled with DSF-Liposomes (DSF-Lipo), CMZ-Liposomes (CMZ-Lipo), PRX-Liposomes (PRX-Lipo), 0.1\% DSF Suspension (DSF-Susp), 3.0\% CMZ Solution (CMZ-Soln), and 0.03\% PRX Solution (PRX-Soln). Thirteen-day old rats were instilled with $5 \mu \mathrm{L}$ of the formulations into both eyes at $1.5 \mathrm{~h}$ before sodium selenite-injection (19 $\mu \mathrm{mol} / \mathrm{kg}$ ) and 4 times per day after sodium selenite-injection. The instillations were continued for one week. The slit images were taken at $96 \mathrm{~h}$ after the sodium selenite-injection. Control shows rat pup without selenite injection.

the nuclear portion of the lens. The slit images of lenses were digitized and the results are presented in Fig. 3. The lens opacities from selenite-injected rats treated with DSF- or CMZ-liposomes were less than $60 \%$ of those levels in the selenite treated positive control group. No anti-cataract effect was observed using $0.1 \%$ DSF suspension, 3.0\% CMZ solution, $0.03 \%$ PRX solution or PRX-liposomes.

The effect of DSF- and CMZ-liposomes on the GSH, $\mathrm{Ca}^{2+}$ contents and the $\mathrm{Na}^{+} / \mathrm{K}^{+}$ratio in lenses of selenitetreated rats is shown in Fig. 4a, b, c, respectively. Significant preservation of the GSH content by pre- and post-treatment with DSF- or CMZ-liposomes was observed. However, instillation of the other preparations had no effect on lens GSH content. The $\mathrm{Ca}^{2+}$ content in the selenite-treated positive control lenses was

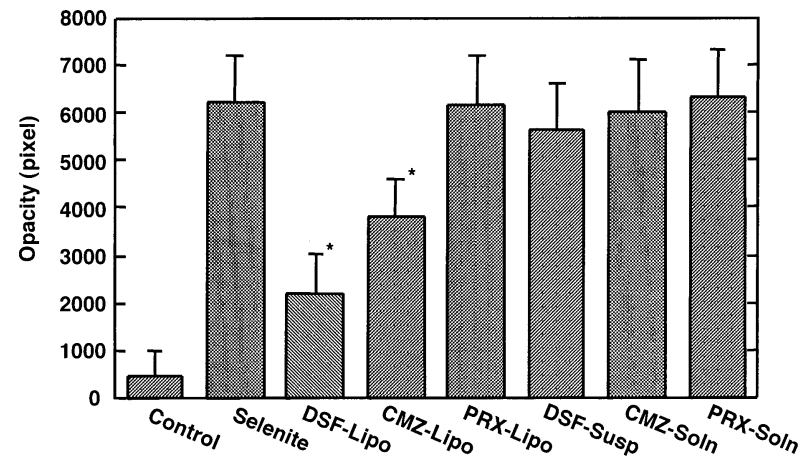

Fig. 3 The Effect of Instillation of DSF-Liposomes, CMZLiposomes, PRX-Liposomes, 0.1\% DSF Suspension, 3.0\% CMZ Solution and 0.03\% PRX Solution on the Opacification of Lenses in Rat Pups $96 \mathrm{~h}$ after Sodium Selenite-Injection. The experiment was carried out under same conditions described in Fig. 2. Each value represents the mean \pm SEM of 8-12 rats. ${ }^{*} p<0.01$ versus Selenite group.

elevated to approximately 5 times the level observed in the non-treated lenses. The instillation of DSF- and CMZ-liposomes $(1.05 \pm 0.41$ and $1.31 \pm 0.36 \mathrm{mM}$, respectively) restored the $\mathrm{Ca}^{2+}$ content to normal level $(0.82 \pm 0.32 \mathrm{mM})$. There was no effect on the lens $\mathrm{Ca}^{2+}$ content in the other treated groups. In particular, two formulations of PRX had no effect on GSH and $\mathrm{Ca}^{2+}$ levels. There were no differences between the $\mathrm{Na}^{+} / \mathrm{K}^{+}$ratios in lenses with and without anti-cataract agents, and the ratios were almost the same as that observed in the normal rat lens.

\section{Discussion}

Selenite-induced cataracts in rat pups is a rapid and convenient animal model for the development of cataracts and is widely used for the initial screening for potential anti-cataract agents (28). Although the mechanism of selenite-induced lens opacification is still unclear, selenite has been reported to generate ROS including the superoxide anion and the hydroxyl radical (36). Accumulation of $\mathrm{H}_{2} \mathrm{O}_{2}$ and decreased GSH are observed in both the selenite-induced cataracts and human cataracts (37). Devamanoharan et al. reported that treatment with vitamin $\mathrm{C}$ had a preventive effect on selenite-induced cataracts in rat pups (14). However, in their study vitamin $\mathrm{C}$ and selinite were both administered intraperitoneally and the vitamin $\mathrm{C}$ may have 

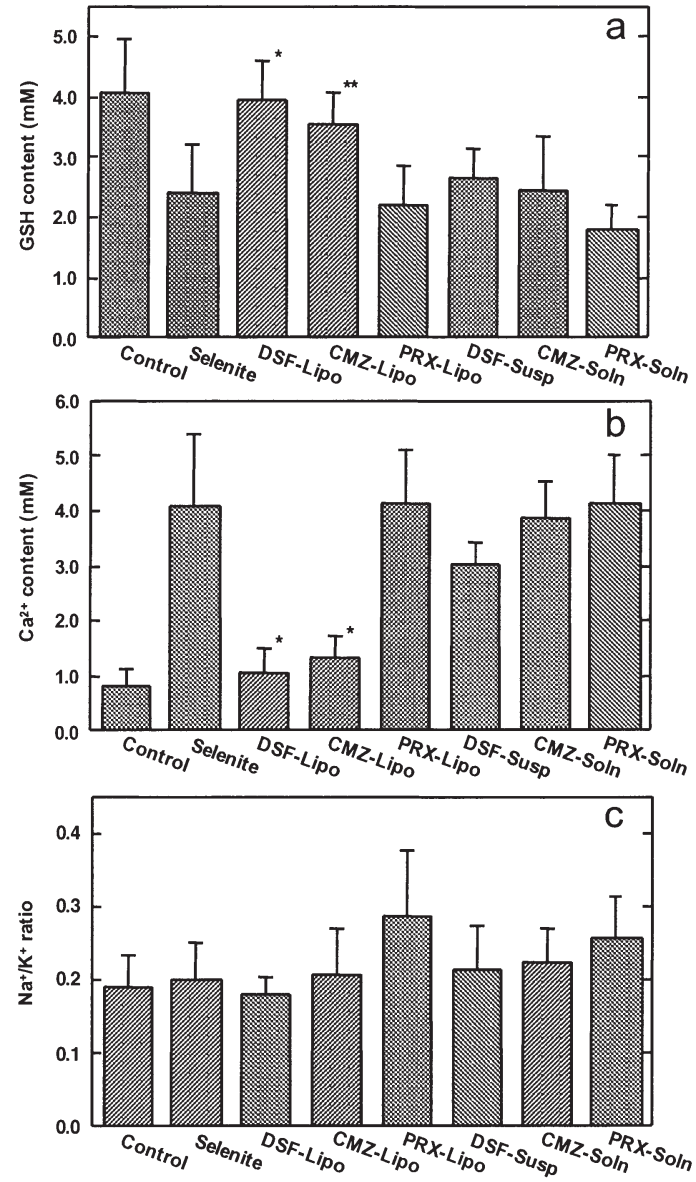

Fig. 4 The Effect of Instillation of DSF-Liposomes, CMZLiposomes, PRX-Liposomes, 0.1\% DSF Suspension, $3.0 \%$ CMZ Solution and $0.03 \%$ PRX Solution on GSH (a), $\mathrm{Ca}^{2+}$ (b) and $\mathrm{Na}^{+} / \mathrm{K}^{+}$Ratio (c) of Lenses in Rat Pups $96 \mathrm{~h}$ after Sodium Selenite-Injection. Each value represents the mean \pm SEM of 8 - 12 rats. ${ }^{*} p<$ 0.01 versus Selenite group; $* * p<0.05$ versus Selenite group.

reacted locally with the selenite. Therefore, in this study we investigated the preventive effect of DSF and $\mathrm{CMZ}$ on selinite-induced cataract development in rat pups by the instillation of liposomes containing these agents into the eyes of the rat pups.

DSF is a lipophilic agent and is encapsuled in the lipid phase of liposomes. The recovery of DSF encapsulated in liposomes was approximately $100 \%$ in this study. On the other hand, CMZ and PRX are hydrophilic agents and were encapsulated in the inner water phase of liposomes. The recoveries of CMZ and PRX encapsulated in liposomes were approximately 3 and $80 \%$ respectively after removing those agents in outer water phase of liposomes by a column chromatography. The higher recovery of PRX than CMZ may be owe to adsorption ability of PRX to the lipid phase of liposome. The similar result was reported for a doxorubicin encapsulated in liposomes (38).

DSF is absorbed rapidly from the gastrointestinal tract but no or only a small amount of the DSF appears in blood because it is rapidly reduced to DDC, an active metabolite of DSF, by glutathione reductase in erythrocytes and by the non-enzymatic reduction associated with the albumin sulfhydryl groups $(19,22)$. Our previous experiments had demonstrated that after instillation of DSF-liposomes into rabbit eyes, only DDC was detected in the aqueous humor (29), suggesting that a liposome formulation was effective for the transcorneal delivery of DDC. The similar result was obtained for CMZ-liposomes. Cephamycin antibiotics such as CMZ are degraded non-enzymatically in a neutral or acidic solution to thiomethyltetrazole, that possesses reductive and/or antioxidative activity (23). Therefore, the metabolite may act as an anti-cataract agent.

There have been several reports that PRX had antioxidative activities in in vitro experiments $(39,40)$. It was proposed that PRX may have specifically scavenged the superoxide anion. The effects of DSF and CMZ on the development of selenite-induced cataracts in rats were compared with PRX because it is the most widely available preparation in Japan for the treatment of senile cataracts (25-27). However, some investigators have reported that PRX was not effective for the treatment of human cataracts $(41,42)$. In this study we used PRXliposomes and a PRX solution at 5 and 6 times the concentration used clinically. The anti-cataract effect by PRX was not observed (Fig. 4).

Control of the level of $\mathrm{Ca}^{2+}, \mathrm{Na}^{+}$and $\mathrm{K}^{+}$ions is essential for lens function. $\mathrm{Na}^{+}, \mathrm{K}^{+}$-ATPase and $\mathrm{Ca}^{2+}$-ATPase in the epithelial cells of the lens membrane maintain the levels of these ions in the lens. Increased levels of $\mathrm{Ca}^{2+}$ and $\mathrm{Na}^{+}$have been reported in many cataractous lenses (43). In contrast, Shearer et al. reported that there was an elevation of $\mathrm{Ca}^{2+}$ but no increase of the $\mathrm{Na}^{+}$content in the lens of selenite-injected rat pups (44). Similar results were observed in our study (Fig. $4 b$, c). Instillations of DSF- and CMZ-liposomes suppressed the increased $\mathrm{Ca}^{2+}$ content in lenses of selenite injected rat pups (Fig. 4b). These results suggest that the restoration of the $\mathrm{Ca}^{2+}$ content in the lens to near normal levels may be the result of protection of $\mathrm{Ca}^{2+}$-ATPase activity 
by DSF and CMZ (45).

\section{Conclusion}

We demonstrated that DSF and CMZ have anticataract effects in the selenite-induced cataract in rat pups. The liposome formulations of DSF and CMZ were more effective than suspensions and solutions in treating the selenite-induced rat cataracts. We plan to investigate methods to stabilize the DSF- and CMZliposomes and to potentially develop more effective formulations such as emulsions and solid dispersions for increased transcorneal penetration by these compounds.

\section{Acknowledgments}

We are most grateful to Dr. John Lund at Pfizer-Pharmacia Corp. (U.S.A.) for comments and suggestions to our manuscript. The studies were supported in part by the Pharmaceutical Research and Technology Institute of Kinki University.

\section{References}

1. B.V. WORGUL, J. DAVID, S. ODRICH, S.L. TROKEL and C.R. GERARD, Evidence of Genotoxic Damage in Human Cataractous Lenses, Mutagen, Vol. 6, 495-499 (1991).

2. N.J. KLEIMAN and A. SPECTOR, DNA Strand Breaks in Single Human Lens Epithelial Cells from Patient with Cataract, Curr. Eye Res., Vol. 12, 423-431 (1993).

3. A. SPECTOR, The Search for a Solution to Senile Cataracts, Invest. Ophthalmol. Vis. Sci., Vol. 25, 130-146 (1984).

4. K.C. BHUYAN and K.D. BHUYAN, Molecular Mechanism of Cataractogenesis. II. Evidence of Lipid Peroxidation and Membrane Damage, in Oxy Radicals and Their Scavenger System (R.A. GREENWALD and G. COHEN, ed.), Elsevier Science Publishing, New York, pp. 349-355 (1983).

5. A. SPECTOR, The Lens and Oxidative Stress; in Oxidative Stress, Oxidants, and Antioxidants (H. SIES, ed.), Academic Press, London, pp. 529-558 (1991).

6. R.C. AUGUSTEYN, Protein Modifications in Cataract: Possible Oxidative Mechanisms; in Mechanisms of Cataract Formation in the Human Lens (G. DUNCAN, ed.), Academic Press, New York, pp. $72-117$ (1981).

7. A. SPECTOR, Oxidative Stress-Induced Cataract: Mechanism of Action, FASEB J., Vol. 9, 1172-1182 (1995).

8. A. TAYLOR, P.F. JACQUES and E.M. EPSTEIN, Relations among Aging, Antioxidant Status, and Cataract, Am. J. Clin. Nutr., Vol. 62, 1439s-1447s (1995).

9. J.J. HARDING, Free and Protein-Bound Glutathione in Normal and Cataractous Human Lenses, Biochem. J., Vol. 117, 957-960
(1970).

10. M.A. BABIZHAEV and A.I. DEEV, Free Radical Oxidation of Lipid and Thiol Groups in Formaion of a Cataract, Biofizika, Vol. 31, 109-114 (1986).

11. A. SPECTOR, G.M. WANG, R.R. WANG, W.H. GARNER and H. MOLL, The Prevention of Cataract Caused by Oxidative Stress in Cultured Rat Lenses, Curr. Eye Res., Vol. 12, 163-179 (1993).

12. F.J. GIBLIN, B. CHAKRAPANI and V.N. REDDY, The Effect of X-Irradiation on Lens Reducing System, Invest. Ophthalmol. Vis. Sci., Vol. 18, 468-475 (1979).

13. S.D. VARMA and R.D. RICHARDS, Ascorbic Acid and the Eye lens, Ophthalmic Res., Vol. 20, 164-173 (1988).

14. P.S. DEVAMANOHARAN, M. HENEIN, S. MORRIS, S. RAMACHANDRAN, R.D. RICHARDS and S.D. VARMA, Protection of Selenite Cataract by Vitamin C, Exp. Eye Res., Vol. 52, 563-568 (1991).

15. I.P. METELITSYNA, I.V. KUU'MENKO, G.I. DROZHZHINA, E.V. MAL'TSEV, N.F. LEUS and G.V. DONCHENKO, AntiCataract Activity of Vitamine E Analog, Ukr. Biokhim. Zh., Vol. 68, 64-69 (1996).

16. T. TAKINAMI, M. ISHIKAWA and S. KITANO, Glutathione in the Crystalline Lens. I. Glutathione Content in the Crystalline Lens of Chick Embryo and Senile Cataract, Nippon Ganka Gakkai Zasshi, Vol. 75, 1630-1636 (1971).

17. A. SPECTOR, W. MA, R.R. WANG, Y. YANG and Y.S. HO, The Contribution of GSH Peroxidase-1, Catalase and GSH to the Degradation of $\mathrm{H}_{2} \mathrm{O}_{2}$ by the Mouse Lens, Exp. Eye Res., Vol. 64, 477-485 (1997)

18. C. WRIGHT and R.D. MOORE, Disulfiram of Alcoholism, Am. J. Med., Vol. 88, 647-655 (1990).

19. T.M. KISTON, The Disulfiram-Ethanol Reaction, J. Stud. Alcohol., Vol. 38, 96-113 (1977).

20. R.P. AGARWAL, R.A. McPHERSON and M. PHILLIPS, Rapid Degradation of Disulfiram by Serum Albumin, Res. Comm. Chem. Pathol. Pharmacol., Vol. 42, 293-310 (1983).

21. J.F. KOSTER and J.C. VAN BERKEL, The Effect of Diethyldithiocarbamate on the Lipid Peroxidation of Rat Liver Microsomes and Intact Hepatocytes, Biochem. Pharmacol., Vol. 32, 3307-3310 (1983).

22. U. KUHNLEIN, Disulfiram Inhibits DNA Breakage by Hydroxyradical-Producing Agents, Biochim. Biophys. Acta, Vol. 609, 75-83 (1980).

23. S. TAKANO, M. TAI, H. SAKAI, I. TAKAKURA, H. OCHIAI, Y. SUGIMOTO, Y. FUKUOKA and I. SAIKAWA, Studies on $\beta$ Lactam Antibiotics for Medicinal Purpose. XIV, Stability and Degradation Pattern of Sodium 7 $\beta$-[(2R,3S)-2-(4-Ethyl-2,3Dioxo-1-Piperazinecarboxamido)-3-Hydroxybutanamido]-7 $\alpha$ Methoxy-3-[(1-Methyl-1H-Tetrazol-5-yl)Thiomethyl]-3Cephem-4-Carboxylate (T-1982) in Aqueous Solution, YAKUGAKU ZASSHI, Vol. 103, 62-72 (1983).

24. S. DRUMMER, W.E. Jr. HAUSER and J.S. REMINGTON, Antabuse-Like Effect of $\beta$-Lactum Antibiotics, N. Engl. J. Med., Vol. 303, 1417-1418 (1980). 
25. T. SUZUKI, Therapeutic Effect of Catalin in Senile Cataract, Jpn. Rev. Clin. Ophthalmol., Vol. 52, 868-871 (1958).

26. T. OKAMOTO, Catalin ${ }^{\circledR}$ Opthalmic Solution in the Treatment of Senile Cataract: An Evaluation by the Transillumination Photographic Technique, Folia Ophthalmol. Jap., Vol. 26, 1335-1345 (1975).

27. K. NISHIZAKI and K. INOUE, Clinical Experiments with High Concentration Catalin Ophthalmic Solution, Folia Ophthalmol. Jap., Vol. 26, 1087-1090 (1975).

28. T.R. SHEARER, H. MA, C.H. FUKIAGE and M. AZUMA, Selenite Nuclear Cataract: Review of the Model, Mol. Vis., Vol. 3, 8 (1997).

29. Y. ITO, H. CAI, Y. KOIZUMI, R. HORI, M. TERAO, T. KIMURA, S. TAKAGI and M. TOMOHIRO, Effect of Lipid Composition on the Transcorneal Penetration of Liposomes Containing Disulfiram, a Potential Anti-Cataract Agent, in the Rabbit, Biol. Pharm. Bull., Vol. 23, 327-333 (2000).

30. MINISTRY of HEALTH, LABOURE and WELFARE, JAPAN, "Pirenoxine," The Japanese Pharmacopoeia, 14th Edition, pp. 628-629 (2001).

31. F. Jr. SZOKA and D. PAPAHADJOPOULOS, Procedure for Preparation of Liposomes with Large Internal Aqueous Space and High Capture by Reverse-Phase Evaporation, Proc. Natl. Acad. Sci. USA, Vol. 75, 4194-4198 (1978).

32. S. TSUNASAWA, Separation of Peptides by Using ODS Column of HPLC, YMC Application Note, No. 2, 1-2 (1991).

33. G.E. BUNCE, J.L. HESS and R. BATRA, Lens Calcium and Selenite-Induced Cataract, Curr. Eye Res., Vol. 3, 315-320 (1984).

34. I. ADAMSONS, K.I. TAYLOR, C. ENGER and H.R. TAYLOR, A New Method for Documenting Lens Opacities, Am. J. Ophthalmol., Vol. 111, 65-70 (1991).

35. M. KOJIMA and K. SASAKI, Application of a New Scheimpflug Camera (EAS-1000) to Animal Cataract Models, Ophthalmic Res., Vol. 24, 3-9 (1992).

36. Y.Y. SEKO and N.M. IMURA, Active Oxygen Generation as a
Possible Mechanism of Selenium Toxicity, Biomed. Environ. Sci., Vol. 10, 333-339 (1997).

37. D.L. BOYLE, D. BLUNT and L.J. TAKEMOTO, Confocal Microscopy of Cataracts from Animal Model Systems: Relevance to Human Nuclear Cataract, Exp. Eye Res., Vol. 64, 565572 (1997).

38. K. YACHI, H. KIKUCHI, N. SUZUKI, R. ATSUMI, M. AONUMA and Y. KAWATO, Pharmaceutical and Biological Properties of Doxorubicin Encapsulated in Liposomes (L-ADM): the Effect of Repeated Administration on the Systemic Phagocytic Activity and Pharmacokinetics, Biopharm. Drug Dispos., Vol. 16, 653667 (1995).

39. N.R. BISWAS, P.K. MONGRE, G.K. DAS, S. SEN, S.K. ANGRA and R.B. VAJPAYEE, Animal Study on the Effect of Catalin on Aftercataract and Posterior Capsule Opacification, Ophthalmic Res., Vol. 31, 140-142 (1999).

40. M. CIUFFI, S. NERI, S. FRANCHI-MICHELI, P. FAILLI, L. ZILLETTI, M.R. MONCELLI and R. GUIDELLI, Protective Effect of Pirenoxine and U74389 on Induced Lipid Peroxidation in Mammalian Lenses. An In Vitro, Ex Vivo and In Vivo Study, Exp. Eye Res., Vol. 68, 347-359 (1999).

41. H. MACLEAN and C.J. TAYLOR, An Objective Staging for Cortical Cataract In Vivo Aided by Pattern-Analysing Computer, Exp. Eye Res., Vol. 33, 597-602 (1981).

42. M. TESTA, G. IULIANO, P. MORTON and A. LONGONI, Topical Benzyl Alcohol Reduces Cataract Surgerry Need: Two Long-Term Double Blind Sudies, J. Ocul. Pharmacol., Vol. 3, 211-225 (1987).

43. J. HARDING, Cataract: Biochemistry, Epidemiology and Pharmacology, Chapman \& Hall, London (1991).

44. T.R. SHEARER, L.L. DAVID, R.S. ANDERSON and M. AZUMA, Review of Selenite Cataract, Curr. Eye Res., Vol. 11, 357-369 (1992).

45. Y. ITO, H. CAI, M. TERAO and M. TOMOHIRO, Preventive Effect of Diethyldithiocarbamate on Selenite-Induced Opacity in Cultured Rat Lenses, Opthalmic Res., Vol. 33, 52-59 (2001). 